Dicenda. Estudios de lengua y literatura españolas

ISSN-e: $1988-2556$

https://dx.doi.org/10.5209/DICE.64992

\title{
El poeta debe morir: fantasía, angustia y violencia en Nos espera la noche de Espido Freire
}

\author{
Samuel Rodríguez
}

Recibido: 25 de enero de 2017 / Aceptado: 4 de diciembre de 2017

Resumen. Este artículo parte de un estudio estético-formal de la novela Nos espera la noche (2003) de Espido Freire (Bilbao, 1974), lo cual implica comprender las peculiaridades espacio-temporales de una mítica y angustiosa ciudad-personaje, Gyomaendrod, que trasciende la tradicional épica y los cuentos de hadas. Asimismo, resulta necesario comprender los resortes del poder y la desgarradora violencia que en él subyace, tanto física como simbólica, con especial incidencia en los personajes femeninos. Finalmente, compondremos un peculiar panegírico al poeta, al arte. Para ello haremos uso de herramientas metodológicas interdisciplinares que incluyen fuentes narratológicas, filosóficas, sociológicas y psicoanalíticas.

Palabras clave: Espido Freire; fantasía; angustia; violencia.

\section{[en] The poet must die: fantasy, anguish and violence in Nos espera la noche by Espido Freire}

\begin{abstract}
This research paper analyses from an aesthetic and formal study the novel Nos espera la noche (2003) by Espido Freire (Bilbao, 1974). This implies to understand the spatial and temporal features of a mythical and anguished city-character, Gyomaendrod, which transcends the traditional epic genre and the fairy tales. In addition, it is necessary to understand the power and his heartbreaking violence, physical and symbolic, especially in female characters. Finally, I will compose a peculiar panegyric to the poet, to art. For that purpose, I will use interdisciplinary methodological tools such as narratology, philosophy, sociology and psychoanalysis.
\end{abstract}

Keywords: Espido Freire; fantasy; anguish; violence.

Sumario: 1. Gyomaendrod, una ciudad-personaje; 2 . Entre novela épica y cuento de hadas. La ambigüedad angustiosa en lo fantástico; 3 . Violencia y dominación masculina; 3.1. La violencia desgarradora de la primavera; 3.2. Dominación masculina; 4. El poeta debe morir.

Cómo citar: Rodríguez, S. (2019). El poeta debe morir: fantasía, angustia y violencia en Nos espera la noche de Espido Freire, en Dicenda. Estudios de Lengua y Literatura Españolas, 37, 9-29.

Dentro de la narrativa española contemporánea, Espido Freire (Bilbao, 1974) se erige como una de las maestras de la sugerencia de la trama y la evocación de atmósferas ambiguas, construidas en un tiempo mítico que roza lo fantástico. Creemos que Nos espera la noche (2003) desarrolla además algunas de sus obsesiones en torno a la angustia,

\footnotetext{
1 Université Clermont-Auvergne/ Universidad Complutense de Madrid samuel.rodriguez.rodriguez@outlook.com
} 
la violencia y la muerte. Podría ser también acaso un opúsculo sobre el arte, sobre el poeta, sobre el visionario que, bien sea a través de la palabra, la música o la desesperada búsqueda de belleza, anhela algo que lo trasciende y, en esa desesperación, sucumbe.

Sin embargo, la investigación académica aún no ha realizado un estudio profundo de la narrativa de Espido Freire, y mucho menos de esta novela, eclipsada por otras obras de la autora. Así pues, deseamos desplegar un original estudio de Nos espera la noche a partir de la hipótesis planteada. Partiremos del análisis estético-formal de la novela, lo cual implica comprender las peculiaridades espacio-temporales de una mítica ciudad-personaje, Gyomaendrod, en torno a la cual la vida se imbrica en una claustrofóbica colmena de angustia que parece trascender la tradicional épica y los cuentos de hadas. Asimismo, resulta necesario comprender los resortes del poder y la desgarradora violencia que en él subyace, tanto física como simbólica, con especial incidencia en los personajes femeninos y la dominación masculina a la que se ven sometidos. Finalmente, compondremos un peculiar panegírico al poeta, al arte. Para ello, haremos uso de herramientas metodológicas interdisciplinares que incluyen fuentes narratológicas, filosóficas, sociológicas y psicoanalíticas.

\section{Gyomaendrod, una ciudad-personaje}

Nos espera la noche es la segunda y por el momento última novela publicada de la "Trilogía de las ciudades", cuya última parte permanece inédita, y que comienza con Donde siempre es octubre (1999). Aunque son obras independientes, ambas nos transportan a un "orfeón” de voces (Senís Fernández, 2009: 309) —ochenta y seis en Donde siempre es octubre y cuarenta y nueve aquí-, entretejidas en un peculiar espacio -Oilea, una ciudad provinciana en Donde siempre es octubre, y en la segunda parte un espacio más rural, Gyomaendrod y sus alrededores-. Su estructura original, semejante a la de Donde siempre es octubre, experimentó importantes transformaciones:

Hace años fui superponiendo historias y entretejiendo hasta veintidós narraciones independientes. Cuando terminé el relato estaba bastante satisfecha, pero me salió una novela altamente experimental, muy fragmentada. Al revisarla, el texto ha perdido radicalidad, pero ha ganado en fondo (Paniagua, 2003).

El resultado es una novela dividida en cinco secciones cuyos títulos aluden a algunos de los personajes más importantes (Bilawal, Sibila, Thonolan, Deagad y Robin). Todos ellos habitan en un espacio, como Oilea, hermético y peligroso. Tras la incursión de Diabulus in musica (2001) en espacios y tiempos concretos, que retomará en Soria Moria (2007) y La flor del norte (2011), aquí Espido Freire vuelve a desplegar su particular geografía imaginaria: Gyomaendrod², el Monte del Gato, Grandale, Oilea, Astaregar ${ }^{3}$ o Desrein, la capital en Melocotones helados (1999).

2 El nombre de Gyomanedrod proviene en realidad de Gyomanedrőd, una pequeña localidad al sureste de Hungría. Sin embargo, la elección de referencias lejanas e irreconocibles (como ya hiciera en otros relatos como "El monstruo de madera" en Juegos míos, 2004, donde se alude a Tiselder, una pequeña ciudad checa) señala la intención de la autora de transportarnos a un espacio igualmente perdido y evocador.

3 Nótese la influencia mitológica en el nombre de esta ciudad, capital de la provincia de Gyomaendrod. Astaregard nos recuerda a Asgard, morada de los dioses en la mitología nórdica. 
Al igual que en Donde siempre es octubre, Gyomaendrod y sus habitantes forman un cuerpo único, personaje principal de tramas insinuadas que, en la mayoría de los casos, no llegan a desarrollarse con profundidad ${ }^{4}$, como tampoco se desarrolla el sustrato histórico-social de la ciudad.

Los espacios y los personajes circunscritos en un tiempo mítico son el marco referencial de atmósferas misteriosas y decadentes, el effet de réel (Barthes, 1968: 84-89) que vivifica y estetiza la realidad trascendida en la literatura por medio de la illusion référentielle (Barthes, 1968: 88). Y es que, como ya subrayó Kierkegaard, a nivel metafísico el tiempo, circunscrito en el espacio, carece de pasado, presente y futuro, "porque cada momento es enteramente lo mismo que la suma de los momentos, un proceso, un pasar" (Kierkegaard, 1959: 85). En el plano narrativo no importa el tiempo ni el espacio, pues en el fondo la trama concreta es un soporte para alcanzar pensamientos universales. Como en Borges, nos encontramos ante un sentido universalizante con dos niveles narrativos: el concreto y el conceptual (Borges, 1980: 269).

En la línea de la anterior aseveración, afirmamos que la originalidad y la maestría de la autora en la creación del espacio narrativo es resultado de su localización imposible en el espacio, de su propia negación, pues el auténtico espacio en el que se desenvuelven sus cuentos y novelas no es sino nuestra mente. Oilea, Gyomaendrod, Astaregard o Desrein no son auténticas ciudades sino un effet de réel, receptáculos de pensamiento, de lo intangible, de lo abstracto.

En Gyomaendrod cada familia constituye un "clan entrelazado como las agujas de un abeto" (Freire, 2003b: 13) con dimensiones cuasi "antropomórficas"5 según Bourdieu, de modo que se acusa una fuerte endogamia y hermetismo, acentuado por los pocos clanes familiares de renombre. Por eso, en palabras de Duarte Juvara, "aquí somos todos familia, de lejos o de cerca, y tendemos a la sangre, y los hijos atan y enredan el ovillo" (98). Esto les lleva a trazar, según veremos, intrincados planes matrimoniales para perpetuarse en el poder. Son cinco familias las que se lo disputan: los Pozbipieta, los Mercian, los Iaunua, los Sverker y los Dianordia. No obstante, prevalece uno de los clanes, los Pozbipieta, y más concretamente su primogénito, Bilawal. Frente a ellos se sitúan los Ralco, como los Taronjí en Primera memoria de Ana María Matute, marcados por la maldad, la violencia y el salvajismo. Pero en la narrativa espidiana los dobles contrapuestos se unen en armonía, pues "animales y humanos, ángeles y demonios, somos todos huéspedes de un universo marchito" (32). Todos ellos están aferrados inexorablemente a la tierra, del mismo modo que los habitantes de Oilea. Así lo expone la curandera Sibila Castabule:

4 A propósito de Donde siempre es octubre y Nos espera la noche, Juan Senís habla de "indefinición argumental", pues "más preocupada parece su autora en captar y dibujar el alma del lugar, con sus reglas y las relaciones entre sus habitantes, que en dibujar el alma de estos últimos, los cuales al fin y a la postre quedan un poco difuminados, quizás porque, como ocurre en esos cuentos infantiles y en esa épica que la autora dice amar tanto, quedan definidos y actúan en función de un solo conflicto" (Senís Fernández, 2009: 302). Esto es así tal vez por influencia del cuento de hadas, latente en la narrativa espidiana, puesto que en él, "la única pregunta importante es saber qué hacen los personajes; quién hace algo y cómo lo hace son preguntas que sólo se plantean accesoriamente" (Propp, 1987: 32; cursivas en el original). Vid. Rodríguez, 2015 b.

5 Bourdieu sostiene que "par une sorte d'anthropomorphisme consistant à attribuer à un groupe les propriétés d'un individu, on conçoit la famille comme une réalité transcendante à ses membres, un personnage transpersonnel doté d'une vie et d'un esprit communs et d'une vision particulière du monde" (Bourdieu 1993: 32).

6 Son palabras del siniestro Reason Sverker. Destacamos la contraposición entre Bilawal/Robin, Sverker/Lautaro, Iria/Dandel, el saludador/Camila, pater Merade/pater Deagad y Adam Dianordia/Adriana Dianordia. Algunas de estas contraposiciones las desarrollaremos más adelante. 
Mira — dijo Sibila, apretando un terrón de tierra-, esto eres tú, Perlita, y soy yo, y esto es Vincavec. Los ángeles van al cielo y los peces al mar, pero los hombres y las mujeres están cosidos a la tierra, porque lo único que sabemos es que un día surgimos entre la sangre y que hemos de acabar en la tierra. Lo que quede antes o después, el cielo y los ríos, eso es cosa de ángeles y de doctores. Pero lo que yo sé es que mientras viva no habrá un hombre de Gyomaendrod muerto lejos de la tierra (Freire, 2003b: 74).

Esta idea remite a la plateada por Noah Seathl en la cita preliminar que la autora recoge a modo de paratexto:

Esto sabemos: la tierra no pertenece al hombre: el hombre pertenece a la tierra. Esto sabemos. Todo va enlazado, como la sangre que une a una familia. Todo va enlazado. Todo lo que le ocurra a la tierra le ocurrirá a los hijos de la tierra. Después de todo, quizás seamos hermanos. Ya veremos (9).

Cobra así sentido el movimiento contradictorio kierkagaardiano que supone "ser el hombre un individuo y, como tal, a la vez él mismo y la especie entera, de tal suerte que la especie entera participa en el individuo y el individuo en la especie entera" (Kierkegaard, 1959: 30). No en vano, para Espido Freire "formamos parte de una colmena, y nuestra responsabilidad no radica únicamente en nuestra supervivencia, sino en la protección común" (Freire, 2013: 200). Sin embargo, el ser humano busca sin descanso el poder a costa de los demás, aunque para ello deba hacer uso de la violencia, tal y como analizaremos en el caso concreto de Nos espera la noche. Tal vez por eso el destino individual está unido trágicamente al colectivo. E intuimos en esta novela y en el conjunto de la narrativa espidiana una apuesta por el sujeto de carne y hueso. En palabras de Mauro Armiño, "el hombre ha de ser individualizado desde la subjetividad propia, identificado con uno mismo, sentido como una parte de sí" (cit. en Casona, 1991: 13-14). Desde este punto de vista, para María Antonia Bel "la historia no debería estudiarse exclusivamente como una evolución de variables empíricas (política, economía, sociedad), sino contando también con los sentimientos, vivencias, actitudes" (Bel, 2002: 10), porque cada individuo, como su historia particular, cuentan: "La reflexión histórica tiene que comenzar y acabar por el hombre, por la mujer, cada hombre, cada mujer; el hombre y la mujer como seres concretos, no la entelequia humana" (11-12). No obstante, en Nos espera la noche veremos cómo también la gota maligna individual -Bilawal, Sverker — se puede reproducir hasta destruir todo. De hecho, según Bachelard, “dans l'eau ainsi maléficiée, un signe suffit: ce qui est mauvais sous un aspect, dans un de ses caractères, devient mauvais dans son ensemble. Le mal passe de la qualité à la substance"'(Bachelard, 1947: 189). Reason Sverker construye con delicadeza y amor jaulas asesinas organizadas "en torno a un solo eje, de tal modo que si se quitaba la pieza maestra, todas las demás se derrumbaban" (Freire, 2013: 25). Así también Gyomaendrod, unidas armónicamente sus piezas en una urna claustrofóbica, caerá, como Oilea, ante los resortes individuales de unos sujetos movidos por el mal.

En Diabulus in musica, desarrollada en torno al concepto musical medieval de mismo nombre ${ }^{7}$, Espido Freire ya demostró que el abismo de la finitud está siempre

El "diabulus in musica" se refiere al intervalo de cuarta aumentada, el tritono, que aún hoy está terminantemente prohibido por la armonía tradicional. En el Medievo se consideró el intervalo a través del cual, dentro de un 
en nuestra puerta, aunque la cerremos con mil candados. Podemos aceptarla o, como su protagonista, desesperar por la eternidad. Asimismo, esta aceptación supone romper con la oposición de la ilustración de naturaleza/razón en favor de la ambigüedad angustiosa que, en Nos espera la noche, roza lo fantástico.

\section{Entre novela épica y cuento de hadas. La ambigüedad angustiosa en lo fantástico}

Espido Freire dibujó en su primera novela, Irlanda (1998), un mapa boscoso y misterioso donde la naturaleza interactuaba en los rituales de vida y muerte (vid., Rodríguez, 2015c: 347-366), en Donde siempre es octubre desarrolló un espacio angustioso de voces narrativas en contrapunto sin fin, en Melocotones helados nos enseñó el poder de las historias no contadas, del olvido y de la muerte, y en Diabulus musica se valió de la interdiscursividad musical para adentrarnos en el mal, en la angustia. Pues bien, en Nos espera la noche retoma todos estos elementos en una inquietante atmósfera entre lo épico (que ya inició con Aland la Blanca, 2001) y el cuento de hadas, caracterizado, entre otras peculiaridades, por la indefinición espacio-temporal que ya hemos explicado $^{8}$ (vid., Freire, 2000: 19 y Rodríguez, 2015b). Salvando las distancias, explora como Miquel Palol en Igur Neblí (1994) los mecanismos ocultos del poder y la pasión a través de un "poema épico postmoderno" (García Galiano, 2004: 16). Recuerda también a Olvidado Rey Gudú de su querida Ana María Matute, aunque aquí, según apunta Joaquín Arnáiz, "el espacio mítico está contado sin alterar sustancialmente una realidad física encontrable en una Europa rural del XVIII (desde los soldados dragones a la oligarquía rural), quizá con algunos toques de las Eddas islandesas" (Arnáiz, 2003b: 45). La propia Espido Freire ha resaltado en numerosas ocasiones el gran interés que siempre sintió por el Cantar de los nibelungos y el poema Beowulf (Freire, 2009), que se refleja en las luchas por el poder y los personajes femeninos empleados como moneda de cambio, presentes de modo evidente en su poemario épico Aland la blanca y, a modo de destello, en La última batalla de Vincavec el bandido (2001).

Nos espera la noche es un canto a la fantasía entendida como imaginación desbordante de otros mundos que reproducen estetizados el nuestro, y es que para Espido Freire "la novela española tiene una revolución pendiente: incluir elementos de fantasía [...]. Parece que la literatura fantástica es un pecado que se tiene que purgar a base de costumbrismo y realismo. La narrativa fabuladora sólo se permite en la literatura infantil" (Freire, 2003a). Pero la fantasía es también duda - "le fantastique,

sistema musical de apariencia perfecta, se colaba el diablo. En la novela será el espacio por donde la angustia se apoderará de los personajes.

8 La autora confiesa: "Nunca me contaron cuentos de hadas: mi abuela me hablaba de hechos históricos, algunos de ellos épicos, historias de antes de la guerra, la epidemia de la gripe del 18, y los peligros de los lobos. Fui yo, a través de las lecturas, la que aprendí tradiciones, la que intentaba insuflar un poco de fantasía en un entorno tan real, tan dominado por la muerte (murieron ocho de mis familiares en cinco años, y cuatro más los dos siguientes), por la madurez obligada, por la responsabilidad que contraía con mi familia y con mi soledad. No fui una niña infeliz, pero se debió a una labor consciente y exhaustiva por mi parte de crear un mundo propio y encontrar un poco de equilibrio" (Freire, 2004a: 253). Muchas de las historias que se narran, como reconoce en el paratexto inicial (Freire, 2003b: 7) fueron contadas a la escritora por su abuela: "Mi abuela murió antes de que yo publicara libro alguno. Tenía una peculiaridad: al contar, no le importaba apartarse de la verdad siempre que ello redundara en beneficio de la historia. Mi abuelo era más preciso y riguroso, de forma que gracias a los dos pude comparar la verdad histórica y la novelada” (Paniagua, 2003). 
c'est l'hésitation" (Todorov, 1970: 29)—. Se trata de la duda entre las apariencias, la supuesta realidad e irrealidad pues, acaso como sostuvo Nerval, "quoi qu'il en soit, je crois que l'imagination humaine n'a rien inventé qui ne soit vrai, dans ce monde ou dans les autres" (cit. en Todorov, 1970: 44). La mise en abyme o cajas chinas es el recurso técnico que le permite fabular y aglutinar múltiples historias (Rodríguez, 2014b: 54). Es el caso de la leyenda de la joven Oleander, quien, al ser alejada de su amado, se lanza al río cual Ofelia:

Oleander desapareció, como las mariposas al final del verano. Una tarde gris de bochorno el río onduló y tembló, y trajo a Oleander, que seguía la corriente, flotando de espaldas en el agua, el pelo prendido de algas y con los ojos abiertos desde el fondo de la muerte; pasaba para ir a anidar a la mar. A veces vaga en el río, buscando a su amante (Freire, 2003b: 214).

Más adelante desarrollaremos otras historias introducidas en mise en abyme, como la de la ciega Emelot, Ultrice y su confusión a través de los espejos, o la perturbada Adriana Dianordia y su peligroso jardín. Otro recurso es el uso de voces narrativas, alternando el narrador extradiegético y heterodiegético con el narrador intradiegético/extradiegético y homodiegético, así como la introducción de la duda sobre el tiempo y el espacio hasta rozar la simultaneidad por medio de múltiples anacronías (Rodríguez, 2014a: 411-412). Esto lo apreciamos en el personaje de Sibila, la profetisa que, como Tiresias, confunde y fusiona pasado, presente y futuro:

Sibila recordó ese momento en el monte. Sintió oscurecer y cerró los ojos. Estaba cansada, y no distinguía si había vivido todo aquello ya, o si faltaba aún por llegar. Sólo sentía presagios de muerte y tragedia, y deseó con todas sus fuerzas haberse vuelto loca o no vivir nada ya, no ver ya nada. La habían encerrado en una cáscara hueca, y le era imposible distinguir si Lautaro Pozbipieta estuvo vestido de ángel hace meses ya, o si era dentro de cuatro días cuando le vería con alas (Freire, 2003b: 77).

Evoca así la muerte de Lautaro, que más adelante tendrá "alas" pues será al fin un ángel muerto, de modo que "poco a poco el pasado se confundió con el futuro" (Freire, 2003b: 69). A ella vuelve también la historia del suicida Duarte, que analizaremos al final de nuestro estudio. Pero las historias diseminadas anacrónicamente a lo largo de la novela, del mismo modo que eran ordenadas a través de las noticias de un periódico al final de Donde siempre es octubre, aquí lo serán por medio del cuaderno de notas de Adam Dianordia, el científico soñador que escribe todo cuanto observa y que Bilwal, el nuevo símbolo del poder, lee (Freire, 2003b: 223-238).

Sibila y otros personajes de esta novela viven en la angustia, vinculada al momento y el desgarro kierkegaardianos. Para Kierkegaard, la angustia es "el momento en la vida individual" (Kierkegaard, 1959: 81). Sabe que el momento es concebido por Platón de un modo meramente abstracto, como "no-ser bajo la determinación del tiempo" (82). El momento para Kierkegaard no es únicamente lo contingente, sino el punto en el que confluyen lo infinito y lo finito, una transición constante que, como ya explicamos, impide hablar de pasado, presente y futuro?.

9 "El momento es esa cosa ambigua en que entran en contacto el tiempo y la eternidad, contacto con el cual queda puesto el concepto de la temporalidad, en la que el tiempo desgarra continuamente la eternidad y la eternidad 
La ambigüedad de la indefinición espacio-temporal y la fantasía tiene implicaciones también morales. El bien y el mal se pierden en un todo (nada) angustioso e incomprensible: "Es un mundo curioso éste - murmuró Bilawal - un mundo curioso. Pero ¿qué haremos? No tiene arreglo" (Freire, 2003b: 202). Tal vez el mejor ejemplo lo encontramos en la figura del joven padre Deagad. Él recuerda que, siendo seminarista, tuvo un conflicto con un compañero por su traducción de unos versículos del Génesis. Deagad tradujo: "Y tomando Jacob la tierra, la elevó como un altar, y exclamó iQué venerado es este lugar!" (175). Pero su compañero inició así la traducción: "Despertó Jacob de su sueño, y se dijo ;Qué terrible es este lugar! Es la casa de Dios y la puerta de los cielos" (176). El enfado de Deagad es injustificado, puesto que el texto bíblico original, en una de sus versiones más extendidas en castellano por Casiodoro de Reina, dice lo siguiente:

Y despertó Jacob de su sueño, y dijo: Ciertamente Jehová está en este lugar, y yo no lo sabía. Y tuvo miedo, y dijo: ¡Cuán terrible es este lugar! No es otra cosa que casa de Dios y puerta del cielo. Y se levantó Jacob de mañana, y tomó la piedra que había puesto de cabecera, y la alzó por señal, y derramó aceite encima de ella (Génesis 28: 16-18).

En este sueño Jehová se presenta en casa de Jacob y le ofrece a él y a su descendencia la tierra sobre la que duerme:

Yo soy Jehová, el Dios de Abraham tu padre, y el Dios de Isaac; la tierra en que estás acostado te la daré a ti y a tu descendencia. Será tu descendencia como el polvo de la tierra, y te extenderás al occidente, al oriente, al norte y al sur; y todas las familias de la tierra serán benditas en ti y en tu simiente (Génesis 28: 23-24).

Después despierta y, tras la gran promesa, surge lo "terrible", la angustia en sentido kierkegaardiano, entendida como un abismo ante la posibilidad de la posibilidad o el "vértigo de la libertad"10. La promesa divina del infinito le hace consciente de su pequeñez, de su irreparable contingencia. Es la ambigüedad erigida en sistema: "Yo formo la luz y yo creo las tinieblas, yo hago la felicidad y creo la desgracia" (Isaías 45: 7).

La unión de contrarios aparece también a nivel iconográfico, pues Deagad recuerda que las puertas del seminario "estaban flanqueadas por las cabezas de dos monjes talladas en piedra en el dintel. La de la derecha era flaca y sañuda, la de la izquierda carillena y con los ojos depravados" (Freire, 2003b: 179). Su prédica ideal parte de la esperanza: "Como delfines en el fondo del océano vagamos por el mundo incentivados por la esperanza..." (180), pero como veremos al final de este capítulo (y como se aprecia en toda la novela), no hay lugar para ella. Deagad descubre en

traspasa continuamente el tiempo. Sólo aquí alcanza su sentido la división expuesta: el tiempo presente, el tiempo pasado y el tiempo futuro" (Kierkegaard, 1959: 88).

10 Para Kierkegaard, el ser humano "es una síntesis de lo psíquico y lo corpóreo; pero una síntesis inconcebible cuando los dos términos no son unidos en un tercero. Este tercero es el espíritu" (Kierkegaard, 1959: 44) que participa en una deliciosa contradicción, puesto que está unido irremisiblemente, con placer, a ella: "El espíritu tiene angustia de sí mismo; tampoco puede comprenderse a sí mismo [...]; de la angustia no puede huir, porque la ama" (Kierkegaard, 1959: 45). Y se produce una nueva paradoja, el "vértigo de la libertad", que "surge cuando, al querer el espíritu poner la síntesis, la libertad fija la vista en el abismo de su propia posibilidad" (Kierkegaard, 1959: 61). Podría no mirar, pero sus ojos no pueden dejar de fijarse en el abismo, porque él mismo es el abismo, un lugar en el que (re)conocerse. 
el viejo padre Mirade - corroído por la avaricia hasta el punto de robar dinero del cepillo - un espejo de sí mismo. Su sacrificio no ha servido para nada "después de haber renunciado a una vida sencilla, a Gadea, a unos hijos, al reconocimiento que su mérito exigía, a la tranquilidad de una vejez que se convertiría en la del hombre derrotado que tenía delante. Y de pronto, lo vio con toda claridad, las puertas del cielo se cerraron para él" (185-186). De esta manera, los dos personajes aparentemente antagónicos se unen desesperadamente por un destino común desalentador. Y es que el mal y la angustia anidan en todos ellos. Las "ratas en el espejo" de Donde siempre es octubre ${ }^{11}$ se reproducen aquí en la rata de los experimentos científicos de Adam, pero la rata está en nosotros: "algo oscuro crece dentro de mí" (236), pues "quizá la realidad sea un espejo en que no reconocemos nuestro propio reflejo" (235), que nos esforzamos en proyectar en los demás. Como para los mortales dioses nórdicos del Ragnarök (vid., Sierra del Molino, 2012: 141) en Diabulus in musica, el destino parece claro: nos espera la noche.

\section{Violencia y dominación masculina}

El "perpetuo e incesante afán de poder" (Hobbes, 1987: 115) desarrollado por Hobbes, junto con la proyección de nuestro propio mal en el otro, sustentan diferentes tipos de violencia, entre los que destaca la dominación masculina. Nos espera la noche ofrece interesantes aportaciones al respecto que han de ser analizadas.

\subsection{La violencia desgarradora de la primavera}

Los estados modernos han creado diques de contención contra el mal criminal, pero el innato "mal radical"12 (Kant, 2007: 6) del ser humano encuentra siempre vías de expresión, más sutiles cuanto menor es la violencia directa. De hecho, "las formas suaves y larvadas de violencia tienen tantas más posibilidades de imponerse como única forma de ejercer la dominación y la explotación, cuanto más difícil y reprobada sea la explotación directa y brutal" (Fernández, 2005: 10). La violencia contra los demás puede ser un medio para saciar nuestra infinita ansia de poder.

Johan Galtung plantea tres tipos de violencia: directa, estructural y cultural (Galtung, 2003: 7). La directa es la violencia manifiesta, evidente. Se puede producir de manera física, verbal o psicológica. La violencia estructural forma parte de los sistemas sociales, políticos y económicos que rigen las estructuras de poder. La violencia directa mantiene una relación inversamente proporcional a la parte del iceberg sumergida, esto es, la violencia cultural o, en términos de Bourdieu, "violencia simbólica”. Dejaremos esta última para el siguiente subepígrafe.

En Nos espera la noche la violencia se hace evidente desde el íncipit:

Marzo era un mes alegre para los Pozbipieta. En veintiséis días cumplían años el padre y uno de los cuatro hijos, y del primero al último no había nadie en Gyo-

\footnotetext{
11 "Ratas en el espejo" es el título de uno de los capítulos-relatos protagonizado por Iverne, una joven de apariencia virginal y piadosa que cuida de la iglesia mientras hay una plaga de ratas. Frente al espejo despliega su propia rata, un alter ego perverso que no es más que el desdoblamiento ficticio de ella misma (Freire, 1999a: 72-81).

12 El "mal radical” se refiere a las raíces profundas del mal en el ser humano (vid., Rodríguez, 2015a: 136).
} 
maendrod que quedara aparte del salvaje entusiasmo con que se entregaban a la fiesta. Se había olvidado la festividad del santo, y ahora todos seguían el culto a los Pozbipieta; la iglesia se arreglaba, compraban vestidos nuevos y en las casas se mataba algún animal. Desde que amanecía el aniversario de Lautaro, el menor, los hermanos subían a la espadaña y avisaban, con más tino que las cigüeñas, que habían derrotado al invierno. Para el último de marzo, el pueblo estaría exhausto por los excesos y delirante, medio cómplice, medio esclavo de los caprichos de un clan entrelazado como las agujas de un abeto (Freire, 2003b: 13).

Si en la primera novela de la trilogía era octubre, el otoño, el mes que marcaba Oilea, aquí es marzo, la primavera. Tanto el otoño como la primavera representan una transición que supone el fin de una etapa y el comienzo de otra. La primavera, como el concierto vivaldiano, se asocia en general a la floración, la eclosión de vida, el color... pero la belleza exige víctimas. Del mismo modo que en La consagración de la primavera (1913) de Igor Stravinsky, se explora aquí el subsuelo de la primavera, las raíces que se retuercen dolorosamente bajo la tierra, el lado oculto de las flores que germinan, de la ciudad, de sus familias, de sus sentimientos ocultos, ya que "au fond de la matière pousse une végétation obscure; dans la nuit de la matière fleurissent des fleurs noires" (Bachelard, 1947: 3).

Cual ménades, todo el pueblo participa "exhausto por los excesos y delirante" en esta confluencia trágica de vida y dolor, en el "salvaje entusiasmo" con que se celebran los cumpleaños del mayor y el menor de los Pozbipieta —el ángel Lautaro, de veintiún años - frente a la época que termina, el invierno "derrotado". Del mismo modo que en La consagración de la primavera, donde encontramos rondas, juegos de las aldeas rivales o danzas rituales en círculos, aquí los personajes se sumergen en ritos paganos hasta mezclarse con los ritos cristianos (Freire, 2003b: 178). Pero los propios ritos cristianos socialmente aceptados son aquí una transposición de los paganos. Así se aprecia en la fiesta en honor del arcángel San Gabriel en Astaregar, en la que "seis hombres se azotaban las espaldas sin descanso, y como los látigos estaban provistos de pequeños cristales la piel se abría y reventaba en ampollas con sangre"13 (174). Bajo las brumas de la fantasía Espido Freire recoge aquí un ritual centenario, el de los "Picaos" de San Vicente de la Sonsierra (La Rioja)" ${ }^{14}$ En la novela también se alude a otra tradición paganizada del cristianismo, el "Día de los Inocentes", en la que "los niños se vestían con las ropas de los mayores, y ordenaban a los padres" (140), que recuerda la llamada "Fiesta de los locos" de Jalance (Valencia), donde niños y jóvenes se visten y maquillan de modo estrafalario y se les da el poder durante unas horas hasta el pícaro "Baile de los locos". De hecho, desde el íncipit encontramos la lucha de poder que también en la naturaleza se debate dentro del constante movimiento de la existencia, con las fricciones de los elementos que

13 La propia autora señala que "el español, tan rígidamente religioso en algunos aspectos, ha mantenido siempre de manera paralela una superstición que a veces se entremezclaba, precisamente con la imaginería católica convencional, un sincretismo que ha variado desde las romerías de origen pagano al trato casi de tú a tú con el diablo de las meigas gallegas" (Freire, 2015: 44).

14 Los "Picaos" se celebran en Semana Santa además de en las conmemoraciones de la Santa Cruz en mayo y septiembre. Desnuda su espalda, los penitentes (“disciplinantes”) se autoflagelan con un látigo de cuerdas de algodón. Uno de los miembros de la cofradía ("práctico") le da doce pinchazos — uno por cada apóstol— con una bola de cera con cristales incrustados. Finalmente, el "práctico" le propina hasta veintitrés golpes en la espalda hasta hacer brotar la sangre. 
participan en él. Mas el ser humano, como un integrante más de ese constante movimiento, también se retuerce en las entrañas y lucha sin descanso, contra sí mismo y contra los demás. Es "cómplice", de un modo u otro, del mal. Ensalza figuras y las destruye, lucha violentamente por el poder o juzga inmisericorde al que lo ejerce. Bilawal es la figura que lo representa. Si la maldad de Irlanda tenía su equivalente en la legendaria Hibernia (Freire, 1998: 122-123), aquí Bilawal lo tiene en otro ancestro:

Contaban que un antepasado de la madre había sido llevado a juicio por un vecino, acusado del robo de unos potros. Cuando las evidencias lo desmintieron, el vecino se disculpó, retiró todos los cargos, y, reconociendo su error, quiso compensarle regalándole dos fincas. Pozbipieta, con la misma serenidad que había mostrado durante todo el proceso, se negó a aceptarlas; regresó a sus tierras y se prometió con la hermana del vecino. Algún tiempo después, el antiguo acusador apareció acuchillado en el bosque. Pozbipieta se casó, heredó todas las posesiones y no cambió el gesto en el entierro de la esposa, muerta tan joven. Entonces contrajo segundas nupcias con su anterior novia y reinó en sus dominios sin que nadie se atreviera a decir nada (Freire, 2003b: 14-15).

Bilawal encarna en el presente a ese despiadado antepasado, puesto que "esa sangre se mantenía pura en Bilawal, y si se hubiese visto en el mismo caso se hubiera conducido de modo similar al de su antepasado" (Freire, 2003b: 15). Es un "animal pérfido" (15). Además, "manejaba a su antojo a sus hermanos" (14) Darío y Galahad, también "grandes y despiadados" (15), y al joven e inocente Lautaro - el ser puro que ha de morir-, que "pertenecía a la misma raza que Bilawal, esbelto y guapo, pero sin sombras" (15).

No es casualidad que los padres - cuyo nombre no se revela- estén ausentes en la práctica totalidad de la novela, salvo unas rápidas referencias al inicio que aluden a un padre huraño y buen jinete, y a una madre de mal carácter, distante y autoritaria (Freire, 2003b: 14). Los Pozbipieta, con Bilwal a la cabeza, son los nuevos dioses a los que el pueblo rinde culto. Emblema de ello es la veleta que Bilawal coloca en la espadaña de la iglesia, pues ahora todos obrarán al arbitrio del primogénito de los Pozbipieta: "Se sentó bajo las campanas, y sintió en las manos el musgo y el barro de las piedras tras la lluvia. Tenía el cementerio en oscuridad a su espalda, y todo el mundo a sus pies"(49).

Al igual que los dioses nórdicos, los Pozbipieta son mortales, y su destino es el Ragnarök que les aguarda a sus espaldas, el crepúsculo infinito. El poder es efímero, y el pueblo - el ser humano- cambiante: "Ahora nos admiran; pero si los Ralco nos acuchillasen por la espalda, nadie sentiría piedad por nosotros. Existe una cumbre, y alguien ocupará la cumbre, el que llegue primero. Ahora la ocupo yo" (Freire, 2003b: 211). Los habitantes de Gyomaendrod se polarizan en clanes familiares en lucha histórica por el poder. También los niños Ralco heredan el odio de padres y abuelos, quienes les transmiten sus propias leyendas negras:

Las tierras que rodeaban Grandale eran feudo de los Pozbipieta, y si los Pozbipieta les sorprendían allí les arrancarían la piel a tiras durante días, porque no tenían piedad ni siquiera con los niños. Las madres de los Ralco les contaban las atrocidades cometidas por Bilawal Pozbipieta, las tierras arrebatadas a los que las cultivaban, los muertos que había desenterrado, y la historia del monte robado, y les hacían prometer que no se acercarían a Grandale (Freire, 2003b: 249-250). 
A su vez, los Ralco extorsionan, roban y siembran el miedo entre los habitantes de Gyomaendrod. Jasar Ralco incluso intenta violar a Perla Durach, aunque su hermano Denholm lo mata. La madre no duda en cocinar el cadáver y ofrecérselo como manjar a los Ralco, aunque ellos lo descubren y les declaran la guerra. La violencia, por tanto, no terminará jamás.

\subsection{Dominación masculina}

Si la violencia física, directa, deja marcas en la piel, la violencia cultural (según Galtung) o simbólica (según Bourdieu) deja marcas en el alma. La dominación masculina es una de las expresiones más peculiares de la violencia simbólica, que Bourdieu define como "violence douce, insensible, invisible pour ses victimes mêmes, qui s'exerce pour l'essentiel par les voies purement symboliques de la communication et de la connaissance ou, plus précisément, de la méconnaissance" (Bourdieu, 2002: 12). Los agentes que la ejecutan pueden ser concretos (hombres, pero también mujeres que ejercen la violencia simbólica o física en el ámbito de lo doméstico y cotidiano) e instituciones (la familia, la Iglesia, la Escuela y el Estado) (Bourdieu, 2002: 55). Todos contribuyen a la disfunción social de sexos, a los tópicos y a la desigualdad. La violencia simbólica se construye a partir del capital simbólico, que "es una propiedad cualquiera, fuerza física, riqueza, valor guerrero, que, percibida por unos agentes sociales dotados de las categorías de percepción y de valoración que permiten percibirla, conocerla y reconocerla, se vuelve simbólicamente eficiente, como una verdadera fuerza mágica" (Bourdieu, 1999: 172-173). Esto crea un poder también simbólico que Bourdieu define como "ce pouvoir invisible qui ne peut s'exercer qu'avec la complicité de ceux qui ne veulent pas savoir qu'ils le subissent ou même qu'il l'exercent" (Bourdieu, 1977: 405).

La proyección del mal en el otro, en la mujer, forma parte de la dominación masculina (Bourdieu, 2002: 11), que para Alicia Puleo "posee dos funciones: justifica la discriminación y explotación sobre ciertos grupos y canaliza sobre fáciles chivos expiatorios la ansiedad y frustración" (Puleo, 1997: 168). La mujer se convierte así, siguiendo a René Girard, en el "bouc émissaire, cet innocent qui polarise sur lui la haine universelle" (Girard, 1985: 13). Esa haine universelle podría estar relacionada con la insaciable sed de poder según Hobbes, y la proyección de la codicia de ese poder en el otro contra el que se actúa por adelantado, por si acaso (vid., Rodríguez, 2015a: 138-140).

La dominación masculina implica, como ocurre en general con la violencia simbólica, deshumanizar al otro o, al menos, hacerlo inferior, dentro de un grupo de entes indiferenciados unos de otros, ya que "una de las características de la constitución del Otro en tanto lo Otro de lo Uno - sujeto que enuncia - es, justamente, negarle la individualidad" (Puleo, 1997: 172). Dentro de la violencia simbólica existe una red o "economía de bienes simbólicos" (Bourdieu, 2002: 65) al servicio del poder también simbólico, a modo de mercancía de intercambio, según se aprecia en las políticas matrimoniales.

En Nos espera la noche Espido Freire desarrolla estos aspectos, que cobrarán aún más protagonismo en Soria Moria y La flor del norte (vid., Rodríguez, 2016a). Aquí Bilawal, como buen estratega y hombre de poder, traza la red de enlaces matrimoniales que permitan unir el clan de los Pozbipieta al de los Ianua, carentes de figura masculina salvo el melancólico Robin, demasiado "femenino" (Freire, 2003b: 278) 
como para ocuparse de las estrategias de poder. Está dispuesto a casarse incluso con la madre, mientras que a sus hermanos les destina a las jóvenes Ianua. Los cuatro hermanos Pozbipieta las visitan para plantearles sus proyectos matrimoniales. La madre, como hará Cecily en Soria Moria, vela celosamente por el matrimonio de sus hijas, a las que sin embargo no deja de criticar: "antes a las mujeres se las educaba mejor. Sabían menos cosas, pero se las educaba mejor" (197). Galahad se casará con la narcisista Iria que, igual que Iverne, no deja de observarse en el espejo, pero "no necesita el espejo - reflexionó Robin- Necesita que la veamos mirarse en el espejo" (208). Frente a ella encontramos a su hermana Dandel, discreta, tímida y despreocupada por su aspecto. Teme que la casen con el cruel Bilawal, aunque finalmente la prometen a Lautaro, el ángel de los Pozbipieta, el único sin sombras.

Mas a Lautaro, en secreto, lo ama Robin, prometido a su vez con Oradea Tyorswsian, prima de los Pozbipieta, aunque cortejada antes por Adam Dianordia, por lo que Sibila — prendada de él_ la odia. Como en "Soldaditos" (Juegos míos), el amor juega caprichoso, perverso ${ }^{15}$. Tal vez, según Sibila, "el amor no basta para solucionar ciertos quiebros del destino" (Freire, 2003b: 99), puesto que "el amor es una mentira, una cadena de mentiras en la que cada uno hace cosas sin importancia y cae de pronto en la cuenta de lo importante que era lo que estaba haciendo" (99).

Precisamente Sibila sufre porque se le niega participar en los rituales de amor y vida: "le dolía el pensamiento de que tenía pocos amigos y de que no se había casado" (Freire, 2003b: 66). En otra ocasión decide salir en mitad de la noche, y Perla, su asistenta, la increpa: "A estas horas [...] sólo se sale a que la preñe a una el viento, como a las yeguas" (68). Pese a estas ofensivas palabras, Sibila piensa que "ojalá fuera el viento lo que trae los hijos" (68). En contraste, su amiga Séfora, casada con Rudiger Mercian y prima de Deagad y Duarte, tiene varios hijos y espera otro. Desea que sea un varón ya que "un hombre, al fin, es un hombre, y las casas no se construyen con niñas" (67). Sibila quiere que la hija pequeña de Séfora recoja su legado, pero ella prefiere bailar coqueta ante ella, como Elsita en Melocotones helados. Y mientras tanto, languidece consumida por la angustia pues, como la Sibila de Cumas, como Cansandra, vive en silencio su dolor: "dicen que soy alegre porque canto y oyen mi risa - dijo-. Para mí, para mí sola me lamento" (97). Y paradójicamente, "el mío es el refrán del médico que murió sin poder curarse" (68). Intenta alejar el tedio y los malos pensamientos que arrastra: "cantaba todo el día, con voz agradable y ligeramente desgarrada, para aturdirse y para que el ocio no le trajera pensamientos tristes y visiones" (66). En sus canciones transmite sus reflexiones más profundas: "Tres mil demonios te lleven/ ¿Por qué estás aquí conmigo? / si es a otra a la que quieres?” (100). Esto es así porque percibe con frustración cómo su amado Adam, que la visita con frecuencia, sigue enamorado de Oradea. Le pide no obstante que la posea, tal vez en un intento desesperado de escapar de la angustia y la soledad de su casa y su jardín, donde las tumbas unidas de sus padres le recuerdan que otros sí encuentran y perpetúan su amor.

Sin embargo, muchas historias de amor no tienen final feliz. Adriana Dianordia está marcada por la culpa y la frustración de no poder darle hijos a Duarte y cumplir

15 En este cuento se narra una historia de amores imposibles. La adolescente Gracia está enamorada de Martín, un dentista de sentimientos ocultos, homosexual. Daniel, el asistente adolescente de Martín, está enamorado de Gracia. El joven Fran, su hermano, esconde con pudor su amor puro e imposible hacia Daniel. Finalmente, Martín abusa sexualmente de Daniel. Se trata de una red de amores trágicamente tejidos, donde la autora enfatiza el amor homosexual de Fran, cuyo vínculo con Daniel se limita, para su desgracia, a su pasión común por los soldaditos y por la función de celestina respecto a Gracia que Daniel le encomienda a Fran. 
con las expectativas que, como mujer, se espera de ella: "Nuestro matrimonio se acabó la tercera vez que se me deshizo el vientre en sangre" (Freire, 2003b: 169). Finalmente, sufre enajenada el suicido de su marido y la muerte de otros seres queridos. Al igual que Ofelia y la protagonista de Diabulus in musica, sus referentes masculinos han desaparecido, y ella enloquece en torno a sus fantasmas congregados en el jardín: "No sé, no sé ni qué resortes pudo invertir Duarte ni qué pecado debo purgar para tener el jardín lleno de figuras que gesticulan y forman corro [ ]. Marido, escuela, gato, hermano. Palabras sencillas. Me duele, me duele y tengo miedo" (170-171).

También se mueve entre la confusión y el miedo Estejarda, la mujer del conde Athairfada. De gustos estrafalarios, melancólica y taciturna como Loredana Esse en Donde siempre es octubre, la condesa da fiestas para atajar el tedio pero termina manteniendo prácticas incestuosas con su medio hermano y, finalmente, se queda viuda y loca, mientras el espectro de su marido cabalga por la finca. Más misterioso aún es el caso de la supuesta violación que Ultrice Himbere - cuyo padre trabajó para los Athairfada - creyó vivir de pequeña a manos de Adam Dianordia. Le pide a su marido Thonolan que lo mate, pero él descubre que en realidad no fue Adam sino Jasar Ralco, y no le sucedió a ella sino a Emelot, que tenía la habitación llena de espejos reflejados a través de la ventana en la habitación de Ultrice (Freire, 2003b: 140-145). Así, el espejo se convierte aquí, al igual que en otros textos de Espido Freire (vid., Rodríguez, 2014b: 51-61 y Rodríguez, 2016b: 561-574), en un instrumento misterioso que nos enfrenta a nuestro propio yo pero también a otros, confundiendo realidad y fantasía. Su vida, construida a través de retales confusos, se resquebraja:

Estoy confusa. Ya no sé qué es verdad y qué no lo es. Ahora me dices esto y comienzo a verlo. Durante estos años me he dicho algo distinto, y lo he contemplado. Si mañana oigo lo contrario, lo creeré también. Recuerdo la cama dorada y el espejo, pero no puedo decir dónde estaban. Se me está abriendo un abismo a los pies, detrás de mí. Desde esta tarde todo lo que he hecho, hablar, irme de mi casa, unirme a ti, tener una hija, respirar, ha sido consecuencia de aquella cama y aquel espejo. Y tú me dices que estuve equivocada, y ya no sé qué camino he cogido, ni por qué (Freire, 2003b: 146).

Emelot ha construido también su vida mediante reflejos imposibles de espejos que la cegaron y que aún cubren toda su habitación, ante el hartazgo de su hermano Northrop: "Eran diecinueve, cuatro en cada pared y tres en las tablas del armario. Me miraban desde dentro, y mi figura se duplicaba hasta la eternidad. Mis reflejos tenían los ojos hundidos y se movían entre penumbras. Pensé que algún día me atraparían por la espalda" (Freire, 2003b: 216). Es él quien rompe el último espejo de la casa y de ellos salen cientos de cucarachas. Emelot le recrimina: "Siempre les tuviste miedo. Enseñan más de lo que se desea ver" (213). Ella persiste en sus historias, como en sus espejos, que le acercan la verdad eterna confundida entre los misteriosos reflejos: "Sólo cuento lo que ocurrió, las formas en que la vida ocurre y se repite"(214).

Sibila, Ultrice o Emelot encuentran una salida a su opresión en la prometida libertad que ofrece la fantasía. La educación y la sociedad represiva las estigmatizan de por vida y ellas, encerradas en sus habitáculos, perpetúan la voz del profeta que anhela una verdad incomprensible y, tal vez, inasumible. Pero no llegan a alcanzarla, pues el auténtico poeta, el visionario, debe morir. 


\section{El poeta debe morir}

Porque lo bello no es nada

más que el comienzo de lo terrible, justo lo que

nosotros todavía podemos soportar,

y lo admiramos tanto porque él, indiferente, desdeña

destruirnos. Todo ángel es terrible.

Rainer M. Rilke

Tras el espejo hay ratas, sólo ratas. Y cucarachas. No hay consuelo ni esperanza. Las puertas del cielo permanecen cerradas, y sólo nos espera la angustia, tiempo eterno y vacío, la noche. Si en Aland la blanca el intrépido Jantes muere en busca de un mundo ideal perdido, en Nos espera la noche los héroes son los poetas, los seres sensibles capaces de trascender el infinito deseo de poder pero que, como visionarios, han de pagarlo con la muerte. Duarte, el músico, Lautaro, el ángel puro, y Robin, el melancólico, el poeta, componen el triángulo de muertes. Duarte y Robin deciden abandonar la vida plenamente conscientes de su irresoluble desesperación. Lautaro, la frustrada víctima sacrificial, muere con la sencillez de su naturaleza, un simple accidente en mitad del camino.

Duarte Juvara, al igual que la protagonista de Diabulus in musica y los estoicos, se corta las venas y se desangra hasta morir. Su mujer lo ha abandonado y la vida, que nunca tuvo sentido, se le hace ahora demasiado dolorosa. La fe y su piadosa familia - su hermano es el padre Deagad y dos de sus hermanas son monjas - no son un consuelo. Ni siquiera sus partituras y el sonido obsesivo de la gramola calman su angustia. Vive obsesionado con la música de Loeffer y su Opus 14, Un poema pagano, que nos recuerda al atormentado Leverkühn de Thomas Mann. La música, el lied —“canción" y "poema" en alemán — es la máxima expresión poética: "Lo intangible, lo no explicable, sólo puede abordarse mediante palabras sin sentido: mediante poesía, en definitiva" (Freire, 2001d: 10) porque, según el esteta Gustav Aschenbach, "la palabra sólo puede celebrar la belleza, no reproducirla" (Mann, 1996: 67). Desde Homero, Arquíloco o Terpandro, pasando por las canciones provenzales, las cantigas alfonsinas o los villancicos del Cancionero de Palacio hasta los lieder de Schumann, Mahler o Berg, música y palabra están unidas inexorablemente en una simbiosis necesaria. En este caso, para Espido Freire la palabra en prosa implica "un esfuerzo de racionalización mucho más evidente, mucho más marcado por las necesidades de la historia" (Freire, 2001d: 10), pues "ninguna de las artes apela con tanto acierto a la mente, a la acción reposada y peligrosa de meditar, como la literatura" (Freire, 2015: 55). Sin embargo, "no posee la capacidad de evocación de la música, no trae el pasado al presente como ella hace", puesto que "quien escucha música siente" (55).

Por otro lado, la música no sólo remite al mundo sensible. Nietzsche sostiene a partir de Schopenhauer que, a diferencia de la palabra, símbolo de las apariencias, la música es capaz de trascender la finitud del ser humano y alcanzar la esencia de las cosas, la "Voluntad inmaterializada"16. Mas la música, el arte, la belleza, exige

16 Así lo explica Nietzsche: "la música difiere de todas las demás artes en que no es la reproducción de la apariencia, o mejor dicho, de la adecuación objetiva de la voluntad, sino la imagen inmediata de la voluntad misma, y representa así, frente al elemento físico, el elemento metafísico del mundo; al lado de toda apariencia, la cosa 
víctimas. Duarte abandona la vida acompañado por el Poema pagano de Loeffer, y es su mujer quien encuentra el cadáver:

Cuando descubrimos a Duarte, yo tuve que volver de nuevo la vista para no encontrar que era él el de la sangre movediza sobre las losetas del suelo. Lloré más tarde, pero entonces él extendía sus venas en aquella habitación y yo no quise mirarle ni interrumpir la gramola que sonaba decrépita, girando en la misma obra, siempre la misma, la Opus 14 de Loeffer, como cuando estaba vivo (Freire, 2003b: 169).

La música se convierte en su particular monstruo que, al igual que en "El monstruo de madera" (Juegos míos), lo engulle y lo hace suyo, consumada así su ansia de belleza y su angustia. En Espido Freire las referencias musicales, además de contribuir al effet de réel, permiten trascender la apariencia de las palabras y alcanzar la metafísica del mundo, la "música materializada".

Precisamente Lautaro, como el Tadzio de La muerte en Venecia, encarna el ideal estético, la perfección de contenido y forma. Es el doble sin sombras de Bilawal, pero acaso también lo sea del siniestro Reason Sverker, un "poeta del mal" de manos transparentes, como Gabriel en Irlanda o Mikel en Diabulus in musica. No muere, mata. Es un "ángel negro" (Freire, 2003b: 32) enclaustrado en la paranoia de su doble perverso, Morten, que crea estructuras metálicas asesinas y perfumes de vitriolo. Sverker es el responsable de rematar correctamente los clavos de la silla de montar de Lautaro, pero no lo hace, el caballo de Lautaro se encabrita, y Lautaro muere. Reason, como Loki, introduce el mal y propiciará la caída del particular Walhalla espidiano. Por él muere Camila, la hija inocente del oscuro saludador, a finales de febrero. A partir de ahí se disemina el infausto de mal agüero, que concluye con la muerte del ser más puro de Gyomaendrod y el suicidio de quien lo ama.

Lautaro es el ángel blanco, modelo incluso para la túnica que las mujeres cosen al San Gabriel de la catedral de Astaregar. A diferencia de sus hermanos "todos le querían, porque quererle surgía como algo natural y él apreciaba a todos, y, moviéndose en equilibrio entre su casa y el mundo, sabía cómo devolver la alegría en las desgracias" (Freire, 2003b: 15). Tras su cumpleaños, Lautaro se ofrece a llevar a Adam el arzel - el caballo maldito - de camino a casa de su prima Oradea. Bilawal le advierte: "si montas el arzel con la silla nueva que te regalamos, anda con cuidado. Parece que le molesta" (239). Lautaro se viste, cual ser virginal listo para el sacrificio, de blanco impoluto. Pero, poco a poco, su traje se llena de manchas. El tiempo huye: "Se me está acabando el tiempo" (244); "Se me está acabando el tiempo. Estoy corriendo en contra del tiempo"17 (246). Por primera vez se introduce la duda, la sospecha, la angustia, en el ángel de Gyomaendrod. Sueña con la paradoja de la libertad recluido en un monasterio abandonado, decorado con la imagen del triunfo del arcángel Miguel sobre el dragón. Fantasea, camino del río, con la misteriosa y

en sí. Podríamos, pues, definir el mundo como música materializada o como Voluntad inmaterializada; y así se comprende por qué la música confiere inmediatamente a todo cuadro, a toda escena de la vida real, una significación más alta, y esto, ciertamente con un poder tanto más grande cuanto más estrecha es la analogía entre su melodía y la apariencia de que se trata. Esto es lo que hace posible añadir a la música un poema como canto, una descripción figurada como pantomima, o las dos cosas reunidas, como en la ópera" (Nietzsche, 2007: 131).

17 La repetición de frases se construye a modo de idea fija en Espido Freire. La reencontraremos poco después en la obsesión de Robin por el mar. Este recurso contribuye a la creación de un clima inquietante, premonitorio, que apunta muchas veces al inconsciente. 
peligrosa Oleander, tras cuya visión mueres: "Entonces no debe de ser más que eso; desaparecer en el reflejo del espejo. La visión del propio rostro en el agua" (243). Pero "entonces la vio, flotando sobre el agua, blanca y aterradora como un espejo sin imagen, siguiendo el curso del río junto a los juncos y los helechos, y las florecillas de azafrán que se deshojaban con la mirada" (244). Esta hermosa recreación de Ofelia perpetúa los ríos de vida y muerte del Siglo de Oro. Y Lautaro muere:

De pronto descubrió que al caballo le manaba, pierna abajo, un hilillo de sangre, y quiso cargar el peso de su cuerpo en otra zona de la silla que no fuera la que hería al animal. Pero su movimiento debió de rasgar la piel del caballo, que relinchó y se espantó de algo sin nombre y lo lanzó al suelo sin apenas permitirse cerrar los ojos. Las piedras del camino se abrieron para él en el último momento. Murió mirando la veleta que los Pozbipieta habían regalado unos días antes a la iglesia (248).

En un guiño cruel, la última visión de Lautaro es el símbolo del pérfido poder que tantas muertes, tanto sufrimiento y angustia provocan. Lautaro nos recuerda a Aliosha en Los hermanos Karamazov, "uno de esos espíritus sinceros que no creen en la perversidad de los demás" (Dostoievski, 1975: 11). Acaso él también sería el ángel que podría redimir a sus crueles hermanos. Pero, como Tadzio, "dicen que los que son así permanecen pocos años en este mundo" (Freire, 2011: 102). Como la niña de La otra casa (1896) de Henry James, la fiesta de cumpleaños de la joven inocente es la antesala del ritual de muerte que nadie puede evitar. También resulta inevitable la muerte de "Pelé" en El metro de platino iridiado (1990) de Álvaro Pombo. Educado en la maravillosa bondad y transparencia de su madre, su muerte es necesaria para restituir el orden roto por el egoísmo de dimensiones monstruosas de los demás personajes - al igual que el del entorno de la pequeña Hedwig en El pato salvaje (1884) de Henrik Ibsen - . La tragedia es necesaria e inevitable, Lautaro no puede escapar a ella. Pero su muerte no redime a nadie. No hay consuelo, ni esperanza. El espectro de Lautaro se une a sus pérfidos hermanos, e invitan a los viajeros a unirse a ellos. Tras la muerte de la única luz de Gyomaendrod, sólo queda la noche.

La luz se apaga también para Robin. Pero el monstruo de la infelicidad y la angustia siempre lo acompañó. Lamenta su excesiva sensibilidad: "Maldijo que su corazón fuera capaz de sentir cada hoja que caía. Sus nervios eran femeninos, y el mundo le daba la espalda sin comprender el sufrimiento que le suponía respirar. Las señales estaban claras, y la muerte esperaba en el salón para recibirle" (Freire, 2003b: 278). De pequeño buscó consuelo en el dolor: "esa noche me colé en el cuarto, abrí silenciosamente el armario y robé la navaja barbera. La palpé con cuidado y me di un tajo en el muslo y otro en el brazo derecho. Me mordía la mejilla para no gritar. Durante mucho tiempo me levanté cada noche para abrirme una herida nueva, y nunca lloré" (191). Ahora rehuye el sufrimiento, por eso "una y otra vez [...] me he preguntado por qué Duarte eligió el dolor y la navaja, como la que yo utilizaba de niño. ¿Por qué no algo tan sencillo como colgarse como una fruta madura? ¿Cuánto dolor soportó cuando sintió correr la sangre?” (192).

Él, como Bilawal, es el primogénito de un importante clan familiar, pero Robin no busca poder para intentar saciar el sinsentido. Tras el infructuoso dolor, la belleza, la pureza e inocencia perdidas son su consuelo. Lautaro las contiene todas en armonía perfecta. Encarna la belleza que eleva el espíritu —el elemento que une la sínte- 
sis contradictoria de lo psíquico y lo corpóreo, lo infinito y lo finito-(Kierkegaard, 1959: 44). Por eso Robin el melancólico es un poeta, porque vive sólo para alcanzar la belleza, está enfermo de belleza y, como para Aschenbach, "la belleza es, pues, el camino del hombre sensible hacia el espíritu" (Mann, 1996: 61). Pero ya dijimos que el espíritu participa de la contradicción pues está unido, con placer, a ella (Kierkegaard, 1959: 45). Robin se hunde así en la contradicción insalvable tras la desaparición de su única posibilidad de redención.

En calidad de personaje trágico, entiende sin verlo que su amado ha muerto: "Entonces algo brilló en el suelo. Se inclinó para recogerlo; era una herradura de caballo. La apretó en la mano y sintió que no podía más. Los árboles extendían sus ramas como si les hubieran prendido fuego, y todo se contagió con la proximidad de la muerte" (Freire, 2003b: 257). Aunque prometido a Oradea, sólo la imagen secreta de Lautaro, amado como poeta en la distancia, parecía colmar su espíritu. Recuerda su imagen frente al mar, y a ella acude cuando la muerte acecha: "El mar, el mar, el mar..." (267); "El mar..." (269, 271 y 273$)$, tal vez porque, como Gustav Aschenbach,

Amaba el mar por razones profundas: por la apetencia de reposo propia del artista sometido a un arduo trabajo, que ante la exigente pluralidad del mundo fenoménico anhela cobijarse en el seno de lo simple e inmenso, y también por una propensión ilícita - diametralmente opuesta a su tarea y, por eso mismo, seductorahacia lo inarticulado, inconmensurable y eterno: hacia la nada (Mann, 1996: 46).

Oradea le avisa: "Si quieres vivir, tendrás que olvidar. Todos vivimos con la muerte" (Freire, 2003b: 264). Robin desprecia su insensibilidad y su incapacidad para amar la belleza de lo sencillo. El abismo se aproxima. El espectro mortal de El caballero de Olmedo o Bodas de sangre reaparece aquí en la figura de un hombre que busca a los suyos, los que han abandonado a los vivos:

Al cruzar la plaza arrojó la herradura sobre la piedra del suelo, y tuvo un sobresalto al oír una voz a sus espaldas.

- Robin.

Encontró a un hombre joven y rubio, que vestía un traje extraño y se apoyaba contra una de las equinas y sonreía. Robin se encaró hacia él y levantó la cabeza.

- Yo soy Robin.

— No — dijo el extranjero, sin dejar de sonreír-. Perdone. Le confundí con alguien muerto. Alguien que creí muerto.

- No esté muy seguro. Aquí todo puede ser.

- ¿En Gyomaendrod?

Robin sonrió.

— En esta vida (265).

La muerte busca a Lautaro... aunque poco después vendrá a por Robin. Así, el día del compromiso de Iria en casa de los Pozbipieta, Robin camina hasta casa, abre la puerta de su habitación en la torre y, como los seguidores de Odín, como Kelsey Akleigh (Donde siempre es octubre), Mikel (Diabulus in musica) y Sigurd (La flor del norte), se cuelga cual fruta madura de lo alto de su habitación, en el centro de un círculo de velas que ahúman las paredes y la suela de su calzado(283). 
Robin, el enamorado de la belleza prohibida, se une a los espectros de los suicidas en la angustia, a Duarte, el músico, el poeta. Robin, Duarte, pero también Lautaro, como Cleobis y Bitón, mueren jóvenes, en plenitud de sus facultades físicas y mentales, en una muerte deseada para los dos primeros pero que, a diferencia de los gemelos griegos, no aporta gloria sino angustia eterna.

$* * * *$

Nos espera la noche se confirma como una pieza clave dentro de la narrativa espidiana en torno a la construcción de atmósferas ambiguas, construidas en torno a un espacio y tiempo míticos que rozan lo fantástico, y que recorren la angustia y la violencia del ser humano en lucha por el poder. La única esperanza posible, la voz del poeta, del visionario, del "ángel terrible", no nos conduce finalmente a la felicidad sino a la desesperación eterna. Ni siquiera el arte logra redimirnos de los quiebros del destino.

"Así somos [...]. Ángeles caídos, historias incompletas, música inacabada" (Freire, 2003b: 294). El mundo, Gyomaendrod, es nuestra jaula mortal. Y es que la realidad puede ser insoportable. Los cuentos, las leyendas, la música, el arte, no sólo sirven como evasión. Tamizan la realidad, la trascienden y la hacen menos incomprensible. "El arte es vida potenciada. Procura un goce más intenso, pero consume más deprisa" (Mann, 1996: 26). Y el riesgo del fabulador, como afirmaba Kierkegaard, es la desesperación absoluta (Kierkegaard, 1984: 60-63). Es el príncipe real convertido en príncipe de cuento, amante de las narraciones y la música, como Ludwig II. Pero el leitmotiv de Sigfrido, del héroe, se sustenta en el del maleficio... el poeta, el visionario, está maldito. Como Quentin en El ruido y la furia, han entendido la síntesis contradictoria del ser humano y no la soportan.

Inmersos en el largo y doloroso camino que es la vida, la rata tras el espejo traspasa el cristal y nos desvela, como el viejo sileno: "Raza efímera y miserable, hija del azar y del dolor, ¿por qué me fuerzas a revelarte lo que más te valiera no conocer? Lo que debes preferir ante todo es, para ti, lo imposible: es no haber nacido, no ser, ser la nada. Pero después de esto, lo mejor que puedes desear es... morir pronto" (Nietzsche, 2007: 58).

\section{Obras citadas}

Alborg, Concha, "Espido Freire: (re)Lectura y (sub)Versión de los cuentos de hadas", en Ángeles Encinar Félix y Kathleen Gleen (eds.), La pluralidad narrativa. Escritores españoles contemporáneos (1984-2004), Madrid, Biblioteca Nueva, 2005, pp. 243-254.

Arnáiz, Joaquín, “La niña que susurraba a los caballos”, La Razón (24.10.2003), p. 45.

Bachelard, Gaston, L'eau et les rêves, París, Librairie José Corti, 1947.

Barrera García, Consuelo, "Fantasía, onirismo y muerte en las novelas de Espido Freire", Huarte de San Juan. Filología y didáctica de la Lengua, 7 (2004), pp. 21-58.

Barthes, Roland, "L'effet de réel”, Communications, 11 (1968), pp. 84-89.

Bel, María Antonia, La historia de las mujeres desde los textos, Barcelona, Ariel, 2000.

Borges, Jorge Luis, Nueva antología personal, Barcelona, Bruguera, 1980.

Bourdieu, Pierre, "Sur le pouvoir symbolique", Annales, 3 (1977), pp. 405-411.

- "À propos de la famille comme catégorie réalisée", Actes de la recherche en sciences sociales, 100 (1993), pp. 32-36. 
—, Razones prácticas. Sobre la teoría de la acción, Barcelona, Anagrama, 1999.

—, La domination masculine (1998), París, Seuil, 2002.

Calderón Concha, Percy, "Teoría de conflictos de Johan Galtung”, Revista de paz y conflictos, 2 (2009), pp. 60-81.

Casona, Alejandro, La barca sin pescador. Siete gritos en el mar, ed. Mauro Armiño, Madrid, Edaf, 1991.

Dostoievski, Fiodor, Los hermanos Karamazov, Madrid, Pérez del Hoyo, 1975.

Fernández, Juan M., "La noción de violencia simbólica en la obra de Pierre Bourdieu: una aproximación crítica", Cuadernos de trabajo social, 18 (2005), pp. 7-31.

Freire, Espido, Irlanda, Barcelona, Planeta, 1998.

-, Donde siempre es octubre, Barcelona, Seix Barral, 1999a.

-, Melocotones helados, Barcelona, Planeta, 1999b.

—, Primer amor, Madrid, Temas de Hoy, 2000.

-, Aland la blanca, Barcelona, Plaza \& Janés, 2001a.

_, Diabulus in musica, Barcelona, Planeta, 2001b.

—, La última batalla de Vincavec el bandido, Madrid, SM, 2001c.

_, "Lucía Etxebarria y Espido Freire. Cara a cara", El cultural (14.3.2001d), pp. 11-13.

_, "Entrevista a Espido Freire", entrevista de Paula Arenas, Prensa cuatro (3.12.2003a), en línea: http://www.espidofreire.com/entr_nosesperalanoche.htm, consultado el 2 de diciembre de 2017.

-, Nos espera la noche, Madrid, Suma de Letras, 2003b.

- "Del bien y del mal. Una entrevista con Espido Freire", entrevista de Christine Henseler, Letras peninsulares, 17 (2004a), pp. 249-258.

—, Juegos míos, Madrid, Alfaguara, 2004b.

—, Soria Moria, Sevilla, Algaida, 2007.

—, "El cuento", conferencia a cargo de Espido Freire en la Universidad Complutense de Madrid dentro del ciclo Escritores en la biblioteca, organizada por el Foro Complutense de la Fundación General de la Universidad Complutense de Madrid y presentada por Ángel García Galiano, 22.1.2009, en línea: http:/www.youtube.com/watch?v=eZ9vfMIQwxY, consultado el 2 de diciembre de 2017.

-, La flor del norte, Barcelona, Planeta, 2011.

-, Los malos del cuento, Barcelona, Ariel, 2013.

—, Para vos nací. Un mes con Teresa de Jesús, Barcelona, Ariel, 2015.

Galtung, Johan, Violencia cultural, Gernika-Lumo, Gernika Gogoratuz, 2003.

García Galiano, Ángel, "La nueva narrativa bilbaína ante el tercer milenio: Espido Freire”, en Ana Elejabeitia Ortuondo, Juan Otaegi et al (eds.), Bilbao. El espacio lingüístico. Simposio 700 Aniversario, Bilbao, Universidad de Deusto, 2002, pp. 455-463.

_, El fin de la sospecha. Calas significativas en la narrativa española (1993-2003), Málaga, Universidad de Málaga, 2004.

Girard, René, La Route antique des hommes pervers, París, Grasset \& Fasquelle, 1985.

Gómez-Elegido Centeno, Ana María, "Voces y presencias femeninas en la literatura de Espido Freire", en Milagros Arizmendi Martínez y Guadalupe Arbona Abascal (eds.), Letra de mujer, Madrid, Ediciones del Laberinto, 2008, pp. 1-29.

Hobbes, Thomas, Del ciudadano. Leviatán, Madrid, Tecnos, 1987.

Kant, Inmanuel, La religión dentro de los límites de la mera razón, Madrid, Alianza, 2007, en línea: http://www.olimon.org/uan/kant-limites.pdf, consultado el 2 de diciembre de 2017.

Kierkegaard, Søren, El concepto de la angustia, Madrid, Espasa Calpe, 1959.

—, La enfermedad mortal, Madrid, Sarpe, 1984. 
Mann, Thomas, La muerte en Venecia. La montaña mágica. Doctor Faustus, Barcelona, Plaza \& Janés, 1996.

Nietzsche, Friedrich, El origen de la tragedia, Madrid, Espasa Calpe, 2007.

Paniagua, Antonio, "Espido Freire publica Nos espera la noche, una novela que evoca los cuentos de hadas", El Norte de Castilla (22.10.2003), en línea: https://espidofreire.com/ index.php?option $=$ com_k2\&view $=$ item \&layout $=$ item $\& \mathrm{id}=69 \&$ Itemid $=349$, consultado el 2 de diciembre 2017.

Propp, Vladimir, Morfología del cuento, Madrid, Fundamentos, 1987.

Puleo, Alicia, "Mujer, sexualidad y mal en la filosofía contemporánea", Revista de filosofía, 14 (1997), pp. 167-172.

Rodríguez, Samuel, "Espido Freire y la renovación del cuento literario español: Aspectos teóricos y estético-formales", Revista Internacional de Estudios Vascos, 59.2 (2014a), pp. 396-419, en línea: http://www.euskomedia.org/PDFAnlt/riev/59/RIEV_59_2_398-422. pdf, consultado el 2 de diciembre de 2017.

_- "Voces y espejos de Espido Freire. Hacia una estética de la perversión en el relato especular”, Acta Hispánica, 19 (2014b), pp. 51-62, en línea: http://publicatio.bibl.u-szeged. hu/5035/1/Katona\%20ActaHispanica2014.pdf, consultado el 2 de diciembre de 2017.

_ , "Hacia los orígenes del mal. Violencia simbólica y personajes femeninos en la narrativa de Espido Freire”, Iberic@l, 8 (2015a),pp.133-148, en línea: http://iberical.paris-sorbonne.fr/ wp-content/uploads/2015/12/Iberic@1-no8-automne-2015-op.pdf, consultado el 2 de diciembre de 2017.

—, "Le conte de fées comme catalyseur du mal dans l'œuvre d'Espido Freire", Gradiva. Réflexions sur les créations au féminin, Pau, Universidad de Pau, 2015b, en línea: http:// gradiva.univ-pau.fr/live/digitalAssets/139/139282_Les_contes_de_f_es_comme_catalyseurs_du_mal.pdf, consultado el 2 de diciembre de 2017.

_- "Trauma y opresión como mecanismos de construcción de la identidad femenina (perversa) en Irlanda de Espido Freire", en Dominika Jarzombkowska y Katarzyna Moszczynska-Dürst (eds.), ¿Decir lo indecible? Traumas de la historia y las historias del trauma en las literaturas hispánicas, Varsovia, Instituto de Estudios Ibéricos e Iberoamericanos de la Universidad de Varsovia, 2015c, pp. 347-366, en línea: http://www.academia. edu/16722561/Dominika_Jarzombkowska_Katarzyna_Moszczy\%C5\%84skaD\%C3\%BCrst_eds._Decir_lo_indecible_Traumas_de_la_historia_e_historias_del_trauma_en_las_literaturas_hisp $\% \bar{C} 3 \%$ A1nicas._Varsovia_Biblioteka_Iberyjska_Instituto de_Estudios_Ib\%C3\%A9ricos_e_Iberoamericanos_de_la_Universidad_de_Varsovia_2015, consultado el 2 de diciembre de 2017.

- " "Arte de amar, arte de matar. Última vuelta de tuerca en torno al mal en La flor del norte de Espido Freire”, Boletín Hispánico Helvético, 28.2 (2016a), pp. 3-28.

- "Perspectivas literarias en torno a la relación entre madres e hijas. Loco con cuchillo de Espido Freire o cómo matar a tu madre frente al espejo", en Gema Areta Marigó, Trinidad Barrera López, Alexandre Roquain et al., Tuércele el cuello al cisne. Las expresiones de la violencia en la literatura hispánica contemporánea (siglos XX y XXI), Sevilla, Renacimiento, 2016b, pp. 561-574, en línea: https://dialnet.unirioja.es/descarga/libro/659005. pdf, consultado el 2 de diciembre de 2017.

Senís Fernández, Juan, Mujeres escritoras y mitos artísticos en la España contemporánea (Carmen Martín Gaite, Espido Freire, Lucia Etxebarria y Silvia Plath), Madrid, Pliegos, 2009.

Sierra del Molino, Rosa María: "El Ragnarök: ¿el final de los tiempos? Apocalipsis o el destino de las potencias en el universo mitológico nórdico", Arys, 10 (2012), pp. 127-146. 
Stravinsky, Igor, La consagración de la primavera (CD), estudio preliminar de Santiago Martín Bermúdez, orquesta filarmónica checa, Karel Ancerl (director musical), Madrid, Diario El País, 2004.

Todorov, Tzvetan, Introduction à la littérature fantastique, París, Seuil, 1970.

Vega, Lope de, El caballero de Olmedo, Madrid, Cátedra, 1984. 